\title{
Silylated-montmorillonite as co-adsorbent of chitosan composites for methylene blue dye removal in aqueous solution
}

\author{
Ozi Adi Saputra ${ }^{a *}$, Kurnia ${ }^{\mathrm{b}}$, Septi Pujiasih ${ }^{\mathrm{b}}$, Vanani Nur Rizki ${ }^{\mathrm{b}}$, Betty Nurhayati ${ }^{\mathrm{b}}$, Edi Pramono $^{\mathrm{b}}$, \\ Candra Purnawan ${ }^{b^{*}}$
}

${ }^{a}$ Master Program in Chemistry, Faculty of Mathematics and Natural Sciences, Universitas Sebelas Maret, Surakarta, 57126, Indonesia

${ }^{b}$ Chemistry Department, Faculty of Mathematics and Natural Sciences, Universitas Sebelas Maret, Surakarta, 57126, Indonesia

Article history:

Received: 26 May 2020 / Received in revised form: 23 June 2020 / Accepted: 24 June 2020

\begin{abstract}
Industrialization plays an important role in the economy of developing countries, including increasing community welfare. However, the presence of poorly industrial waste disposal system has brought a negative impact on the environment. Therefore, it is deemed necessary to overcome this problem with low-cost technology, namely adsorption. In this research, silylated-montmorillonite (sMMt) has been successfully prepared as supporting material for the adsorption of methylene blue by chitosan. The sMMt was characterized by FTIR, XRD, and elemental mapping techniques. The chitosan/sMMt composites were prepared through dissolution-precipitation method later on producing the rod-like morphology as observed by SEM. The adsorption process was carried out in a batch method by studying the $\mathrm{pH}$ and the adsorption contact time. The adsorption kinetic mechanism of the chitosan/sMMt nanocomposite followed pseudo-second order rather than Lagergren model indicating chemisorption predominant. The addition of silylated-montmorillonite into chitosan then enhanced the methylene blue dye removal performance, evidenced by improving the Qe values by $10 \%$ compared to chitosan.
\end{abstract}

Keywords: Adsorption, chitosan, methylene blue, montmorillonite, silylation

\section{Introduction}

Plastic, textile, dye, leather, cosmetics, pharmaceutical, food, and paper manufacturing industries are the largest contributor in wastewater containing dyes resulted from the coloring process [1]. Channeling of wastewater with a high content of dyes causes serious environmental pollutions, such as inhibiting the photosynthesis process and hampering the growth of aquatic biota [2]. Methylene blue (MB), one of water soluble cationic dyes [3], is the most common dye consumed in dyeing cotton, wood, and silk. In respiratory, MB causes difficulties in breathing. Moreover, it also can cause a permanent damage to the eyes, a burning effect, mental disorders, or excessive sweating, when it directly contacts to the human body $[4,5]$.

Wastewater containing dyes is very difficult to treat due to its molecular size and structure, which makes it resistant to aerobic digestion, stable against light, heat, and oxidation agents [6]. Therefore, an inexpensive, simple and effective treatment should be applied to treat waste water containing dyes from the batik industry to reduce or eliminate any harmful substances. Several well-known methods in the removal of the dye are coagulation-flocculation [7], physical methods [8], physicochemical treatment [9], photocatalytic degradation $[10,11]$, ion exchange [12], and others. However,

* Corresponding author.

Email: oziadisaputra@student.uns.ac.id; candra_pr@staff.uns.ac.id most of them require high operation condition and financial cost. Ngah et al. [13] reviewed some techniques for wastewater containing dyes treatments and elaborated the advantages of adsorption method, such as low cost, easy to operate and effective in dye removal. Moreover, the adsorption process can be performed in chemistry, physics or a combination of both chemistry and physics.

Lately, many researchers have studied the possibility of using low-cost material obtained from nature to remove various types of dyes. Lazim et al. [14] employed orange peel and spent tea leaves as low-cost biosorbent for methylene blue and remazol brilliant blue dyes removal via batch adsorption method. Other biosorbents, such as pineapple leaf and lime peel powder [15], mangosteen peel-based activated carbon [16] and chitosan $[17,18]$, were also reported as promising biosorbent for dye removal.

Chitosan is derived from chitin through deacetylation process. This second most abundant biopolymer is easy to be found in nature and mostly deposited in shells of shrimp, crab, and other shelled animals. Chitosan has good adsorption ability due to its active functional groups such as amines $\left(-\mathrm{NH}_{2}\right)$, hydroxyl $(-\mathrm{OH})$ and cluster glucosamine [19]. This material is relatively abundant in Indonesia, bur still lacks in utilization. The main reason of using chitosan as adsorbent is due to the presence of amines group that could be interacted with dyes molecules, especially anionic dyes, through electrostatic interaction [20-22]. In some cases, such as the 
adsorption of cationic dyes, the chitosan polymer could not optimally adsorb those dyes due to repulsion effect caused by their similar surface charges. Therefore, in some researches, chitosan was composited with another material that has negative surface charges as did Mokhtar and co-workers [23]. Therefore, in this study, to obtain a good performance of chitosan as adsorbent for cationic dyes (methylene blue), modification with negative surface charges materials (such as clay minerals) was performed.

Another abundant material in Indonesian is clay. In the present report, clay can be also employed as adsorbent cationic ions or organic molecules like dyes [24], due to its high surface area and cationic exchange capacity as well as porous structure [25,26]. Sarma et al. [27] used montmorillonite clay as an adsorbent in methylene blue dye removal and discovered a good interaction between dye and clay via surface ionic interaction, which then resulted in high adsorption capacity. Gurses et al. [26] reported the dye adsorption mechanism of montmorillonite clay following the pseudo-second order in which chemisorption was predominant. To enhance the adsorption selectivity and capacity, Some researchers like Nejib et al. [28] modified the clay by adding an additive. The modified clay mineral has a higher adsorption capacity compared to the unmodified one. The modification of clay minerals with organosilane compounds improved the adsorption ability either to anionic or to cationic dyes. Moreira et al. [29] modified the surface of palygorskite and sepiolite with 3-aminopropyltriethoxysilane (APTES), and found a significant improvement on adsorption capacity of modified-clay mineral towards both metanil yellow (anionic dye) and methylene blue (cationic dye). Another investigation also found that organosilane modified montmorillonite has a rapid adsorption performance towards methylene blue. The modification of clay minerals with organosilane compound is aimed not only to improve their adsorption capacity, but also enhance their compatibility to react with polymer matrix like chitosan to create a synergistic effect during adsorption. Herewith, we modified the surface of montmorillonite with 3-glycidiloxypropyltrimethoxysilane (GPTMS) to provide an oxirane ring functional group on their surfaces. This leds a chemical reaction with the amine groups of chitosan via opening ring reaction [30-32]. Consequently, the clay distributed on the chitosan polymer matrix and could improve their adsorption performance towards the methylene blue dye.

In this research, the surface modification of montmorillonite clay with organosilane compound aimed to add an active site and to improve their adsorption ability. To the best of our knowledge, the surface modification by silylation method on montmorillonite and further compositing with chitosan is not studied yet. Moreover, the application of silylated-montmorillonite supported chitosan as adsorbent is also not mentioned in another research. Therefore, we studied the effect of silylated-montmorillonite addition on chitosan toward methylene blue dye adsorption in aqueous solution.

\section{Materials and Methods}

\subsection{Materials}

Chitosan was obtained from PT. Biotech Surindo,
Indonesia. Montmorillonite clay was purchased from Sigma Aldrich (Montmorillonite K 10, surface area 220-270 $\mathrm{m}^{2} \mathrm{~g}^{-1}$ ). Other chemicals, such as 3-glycidiloxypropyl trimethoxysilan (GPTMS, Aldrich), toluene (Merck), ethanol (Merck), hydrochloric acid (Merck), sodium hydroxide (Merck), and Methylene blue (MB) dye were used in this study without any purification or modification except mentioned.

\subsection{Silylation of Montmorillonite}

The silylation method was adopted from Yuan et al. [33] with a slight modification. About $4 \mathrm{~mL}$ of GPTMS was dissolved in $50 \mathrm{~mL}$ of dry toluene. Then, $1.2 \mathrm{~g}$ of montmorillonite clay (MMt) was added and ultrasonically treated for 30 minutes. The mixture was refluxed for $24 \mathrm{~h}$ at $135{ }^{\circ} \mathrm{C}$. The product was filtered and washed several times using fresh toluene to remove any unreacted GPTMS. Then, the final product was dried for $12 \mathrm{~h}$ at $135^{\circ} \mathrm{C}$ and denoted as sMMt. The sMMt product was characterized using FT-IR (Fourier Transform Infra Red) spectroscopy IR prestige 21 SHIMADZHU. The morphology of MMt and sMMt was observed by Scanning Electron Microscopy (SEM, Phenom FEI) and the surface elemental analysis of them was detected by SEM-EDX OXFORD Vega3 LM TESCAN.

\subsection{Synthesis of Chitosan/sMMt composite}

About $2 \mathrm{~g}$ of chitosan was dissolved in $90 \mathrm{ml}$ of $1.5 \%$ acetic acid and then refluxed at $80{ }^{\circ} \mathrm{C}$. Then, the sMMt $(0$ and $20 \% \mathrm{wt}$ ) was added to the chitosan solution and stirred for 1 hour. A liquid form of chitosan or Cs/sMMT composite was slowly dripped into a beaker containing $100 \mathrm{ml}$ of $\mathrm{NaOH} 1 \mathrm{M}$. The precipitates were washed with distilled water and dried at a room temperature for 4 days. The products were then crushed by ball-milling (1000 rpm, 60 minutes), collected and characterized using FT-IR (IR prestige 21 SHIMADZHU) for functional group analysis and SEM (Phenom FEI) for morphological study.

\subsection{Adsorption Study}

The adsorption was performed in room temperature. A total of $20 \mathrm{mg}$ of chitosan, sMMt or chitosan/sMMt composite was added into $10 \mathrm{~mL}$ of conditioned $30 \mathrm{mg} \mathrm{L}^{-1}$ methylene

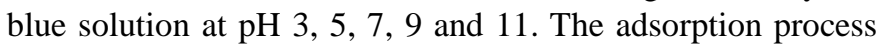
was conducted for 20 minutes. The filtrates were immediately collected and measured by using UV-Vis PerkinElmer Lambda 25 spectrophotometry. From these data, the dye removal was calculated by following equation 1 [14]:

$$
\text { Dye removal }(\%)=((\mathrm{Co}-\mathrm{Ce}) / \mathrm{Ce}) \times 100 \%
$$

Where $\mathrm{Co}\left(\mathrm{mg} \mathrm{L}^{-1}\right)$ and $\mathrm{Ce}\left(\mathrm{mg} \mathrm{L}^{-1}\right)$ are initial and equilibrium dye concentration, respectively.

\subsection{Adsorption Kinetic}

A $30 \mathrm{mg} \mathrm{L}^{-1} \mathrm{MB}$ dye solution was prepared at optimum $\mathrm{pH}$ condition $(\mathrm{pH}=11)$. Then, about $20 \mathrm{mg}$ of chitosan, sMMt or Chitosan/sMMT composite was added to $10 \mathrm{~mL}$ of the MB 
dye solution. The adsorption contact time was varied, i.e. 5, $10,15,20,30,40,50,60,70,80$ and 90 minutes. In this research, the adsorption was performed in room temperature. Afterward, the filtrates of each adsorption at t time were collected and the remaining concentration was measured by using UV-Vis spectrophotometry.

\section{Results and Discussion}

\subsection{Structural Analysis of Silylated-Montmorillonite}

The Surface modification of MMt through silylation method aims to improve the selectivity of clay in dye adsorption as a consequence of an additional functional group (oxirane ring). To find out the success of surface functionalization of MMt, the functional group analysis of origin MMt and sMMt by FTIR was examined. Fig. 1 shows the FTIR spectra of MMT and sMMT. Generally, MMT has a typical peak of hydroxyl $(-\mathrm{OH}), \mathrm{Si}-\mathrm{O}, \mathrm{O}-\mathrm{H}$ deformation of $\mathrm{Al}-\mathrm{OH}, \mathrm{Si}-\mathrm{O}-\mathrm{Al}$ deformation, and the $\mathrm{Si}-\mathrm{O}-\mathrm{Si}$ deformation at $3434 \mathrm{~cm}^{-1}, 1060 \mathrm{~cm}^{-1}, 930 \mathrm{~cm}^{-1}, 525 \mathrm{~cm}^{-1}$, and $469 \mathrm{~cm}^{-1}$, respectively. Some new peaks were observed in FTIR spectra of silylated-MMt. Those peaks appeared at 2939-2880 $\mathrm{cm}^{-1}$, and $693 \mathrm{~cm}^{-1}$, which corresponded to $\mathrm{C}-\mathrm{H}$ stretching vibration and oxirene ring vibration of organosilane compound. According to Herrera et al. [34], the appearance of the typical peak of $\mathrm{C}-\mathrm{H}$ aliphatic on FTIR spectra of clay after modification indicates a bond formation between the silane molecules and the clay through $\mathrm{SiC}-\mathrm{O}-\mathrm{SiC}$ linkage. Additionally, a typical of siloxanes peak was also noticed in FTIR spectra of sMMT at around $1190 \mathrm{~cm}^{-1}$. Based on this characterization, it can be concluded that the MMt has been successfully silylated by GPTMS.

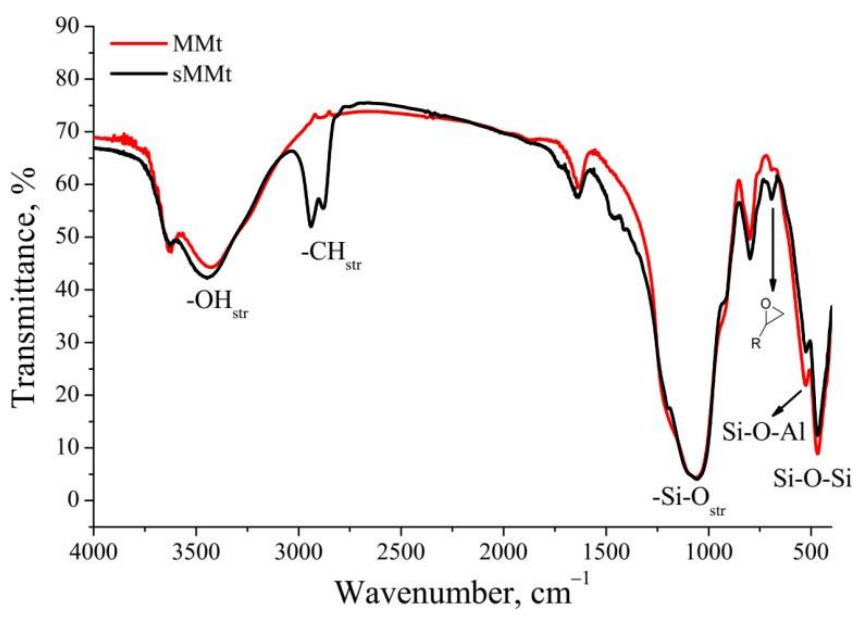

Fig. 1 FTIR spectra of MMt and sMMt

Fig. 2 reveals the X-ray diffraction of the MMt and sMMt. The MMt had a typical peak at 8.7, 19.6, 27.5, 34.7, 45.4, 55.4 , and 61.8 which showed a good agreement with JCPDS no. 03-0015 having a chemical formula $(\mathrm{Na}, \mathrm{Ca})_{0.3}(\mathrm{Al}, \mathrm{Mg})_{2}$ $\mathrm{Si}_{4} \mathrm{O}_{10}(\mathrm{OH})_{2} \cdot \mathrm{xH}_{2} \mathrm{O}$ indicating $\mathrm{K} 10$ structure [35,36]. The quartz phase (JCPDS 74-1811) was also observed in the MMt XRD pattern as impurities. Generally, the XRD peaks of both
MMt and sMMt were similar. However, the intensity of (001) typical peak at $2 \theta 8.74^{\circ}$ decreased as observed in XRD pattern of sMMt. This indicated that the oganosilane compounds mainly attached to this (001) planes. The organosilane formed a siloxane networks on the surface or interlayer of MMt. Consequently, The presence of this poly(siloxane) networks caused the XRD peaks of sMMt seemed broader than MMt, especially in $2 \theta 5-13^{\circ}$, indicating a decrease in its crystallinity compared to MMt.

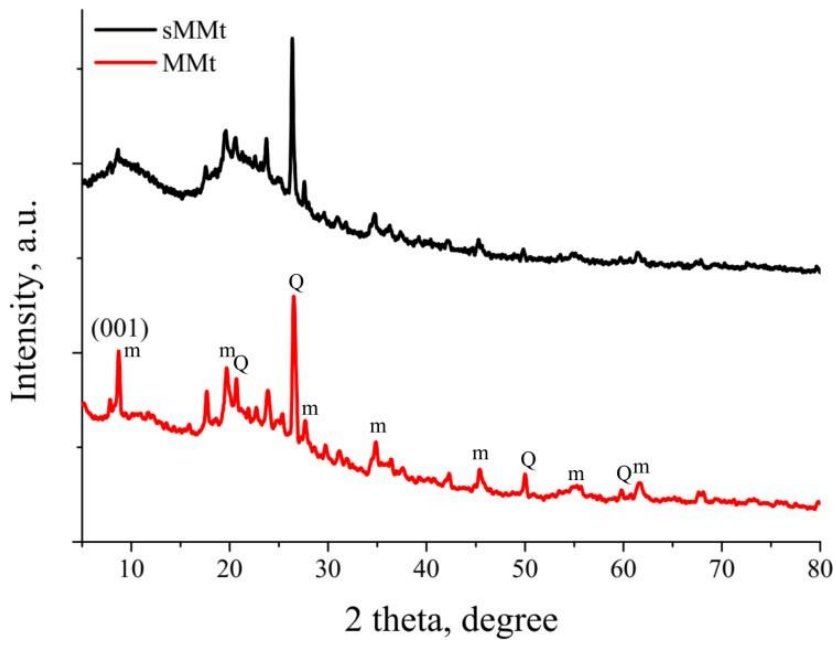

Fig. 2 XRD patterns of MMt and sMMt

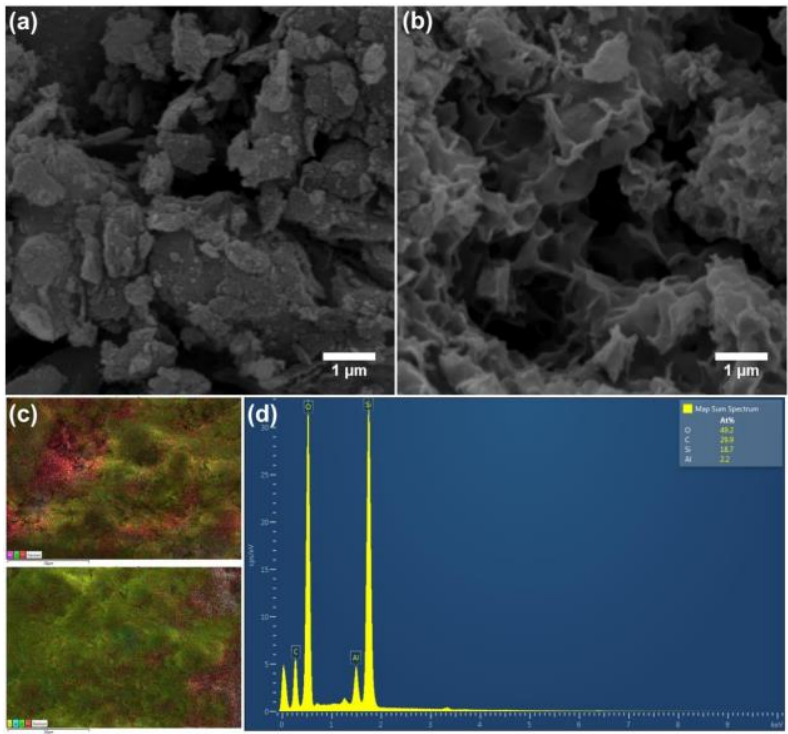

Fig. 3 SEM images of (a) MMt and (b) sMMt. (c) Images of elemental mapping of MMt (up; each colour indicates for $\mathrm{Al}$ (purple), $\mathrm{O}$ (green), and $\mathrm{Si}$ (red) atoms) and sMMt (bottom; each colour indicates Al (blue),

$\mathrm{O}$ (green), Si (red), and C (yellow) atoms). (d) EDX spectra of sMMt

Another characterization supporting the formation of siloxane network of GPTMS on MMT surfaces is morphological analysis by SEM and SEM-EDX. Fig. 3 depicts the morphology of MMt and sMMt. The surface morphology of MMt resembles a plate structure due to its layered-structure (Fig. 3a). Meanwhile, the morphology of 


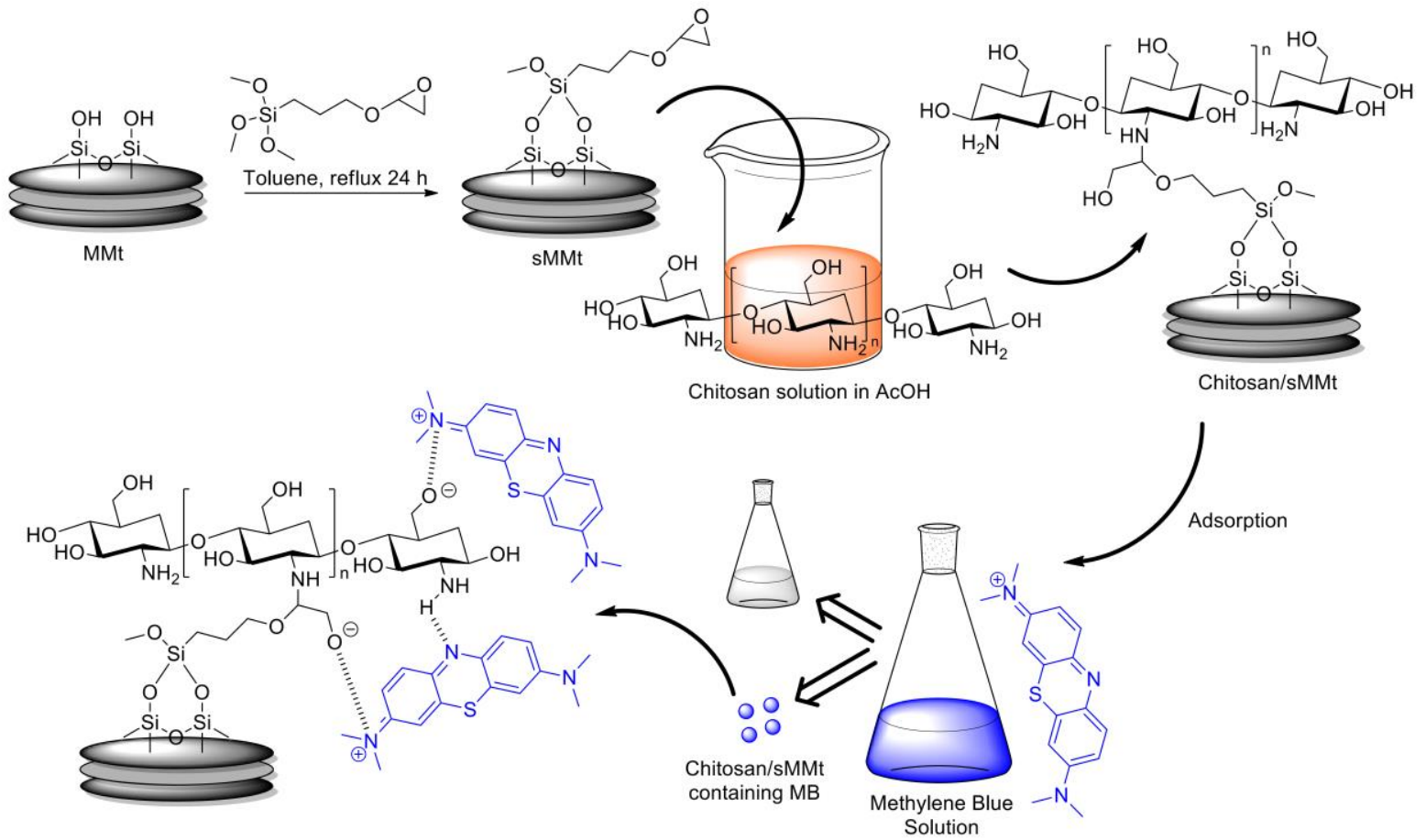

Fig. 4 Proposed illustration of chemical reaction involving chitosan and sMMt. Further, the possible chemical interaction (electrostatic and hydrogen bonding) between methylene blue and Chitosan/SMMt composites is illustrated

sMMt seems to be interconnected sheets as a consequence of the formation of poly(siloxane) on the MMt surfaces (Fig. $3 \mathrm{~b})$. The presence of the siloxane network is able to link MMt plates. Further, the surface elemental analysis of MMt and sMMt recorded by SEM-EDX is used to identify the atomic content on their surfaces. As shown in Fig. 3c, the elemental mapping images of both MMt and sMMt clearly state that the MMT contains $\mathrm{Al}$ (purple), O (green) and $\mathrm{Si}$ (red) atoms with Al to $\mathrm{Si}$ ratio of 4.9:29.7. On the other hand, sMMT has the $\mathrm{Al}$ (blue), $\mathrm{O}$ (green), Si (red) and $\mathrm{C}$ (yellow) atoms on their surface. The presence of $\mathrm{C}$ element on the sMMt surfaces indicates that the surface modification of MMt by GPTMS has been successfully achieved as supported by FTIR and XRD analysis. Based on the EDX spectra (Fig. 3d), the amount of $\mathrm{C}$ atoms on the sMMt surface was $29.9 \%$. Meanwhile, other elements such as $\mathrm{Si}, \mathrm{Al}$ and $\mathrm{O}$ were $18.7 \%$, $2.2 \%$, and $49.2 \%$, respectively. Si:Al ratio of sMMT was $39.3 \%$ higher than Si:Al ratio in the MMT. The increase of the $\mathrm{Si}$ atom occurred due to the contribution of the Si element from GPTMS compound. In addition, the presence of siloxane ( $\mathrm{Si}-\mathrm{O}-\mathrm{Si}$ ) layers on the MMt surface caused a decrease of the Al ratio.

\subsection{Synthesis of Chitosan/sMMt composites}

Chitosan/sMMt composite was prepared through the dissolution precipitation method. The presence of oxirane ring on the surface of sMMt facilitated the chemically interaction to the amine groups of chitosan. The nucleophilic addition was involved in reaction between sMMt and chitosan. The amine group acted as nucleophilic and attacked the oxirane ring [30-32]. Consequently, the chitosan and sMMt were linked via $\beta$-amino alcohol bonds as illustrated in Fig. 4.
Fig. 5 indicates the FTIR spectra of chitosan and chitosan/sMMt. The chitosan had a typical absorbance peak at $1669 \mathrm{~cm}^{-1}$ corresponding to the bending vibration of $\mathrm{N}-\mathrm{H}$ functional group. A broad absorbance band at $3300 \mathrm{~cm}^{-1}$ indicated the $\mathrm{O}-\mathrm{H}$ stretching vibration. All of chitosan typical absorbance band was clearly observed in chitosan/sMMt composites FTIR spectra. However, the $\mathrm{N}-\mathrm{H}$ bending vibration peak slightly shifted to $1687 \mathrm{~cm}^{-1}$ which was probably due to the chemical reaction between the amines group of chitosan and oxirane group on the sMMt surfaces via opening ring reaction as illustrated in Fig 4. Additionally, peaks at $1062 \mathrm{~cm}^{-1}$ and $468 \mathrm{~cm}^{-1}$ corresponded to $\mathrm{Si}-\mathrm{O}$ stretching and $\mathrm{Si}-\mathrm{O}-\mathrm{Si}$ deformation vibration, originated from sMMt.

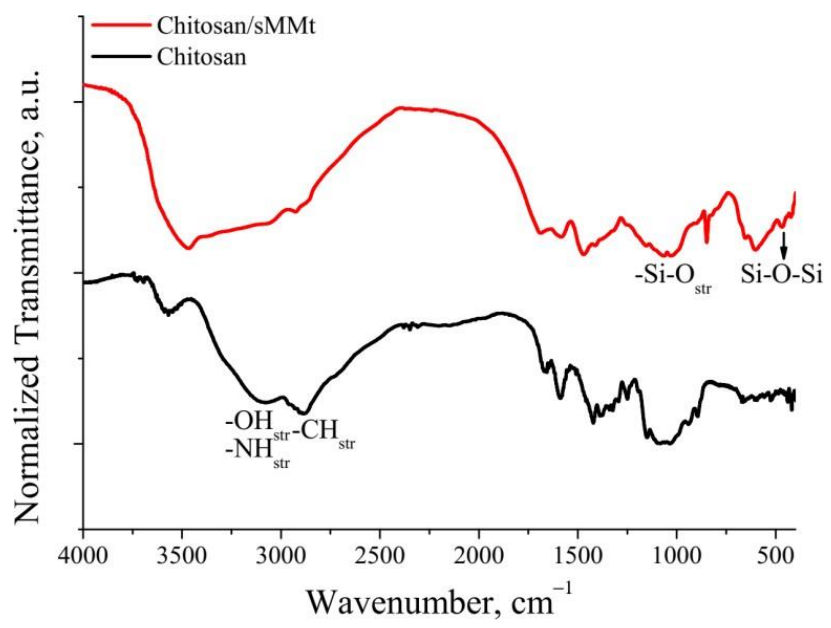

Fig. 5 FTIR spectra of chitosan and chitosan/sMMt nanocomposite 


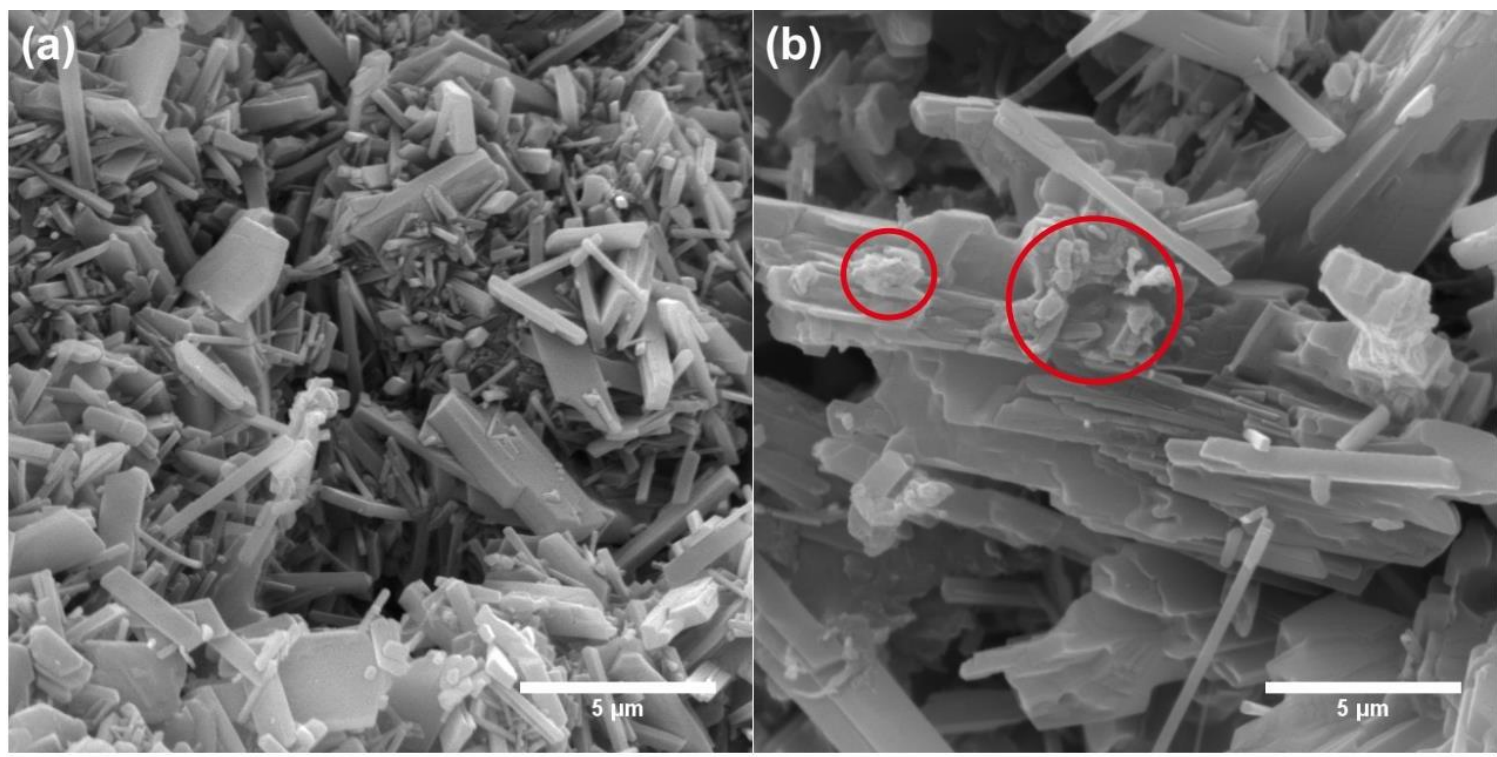

Fig. 6 SEM images of (a) chitosan and (b) chitosan/sMMt. The red circle indicates aggregation of sMMt

The synthesis of chitosan/sMMt composites was carried out by means of dissolution-precipitation method. The solution of chitosan or chitosan/sMMt composites was precipitated in a basic solution to yield a solid form. The immediate solidification process affected the morphological structure of both chitosan and chitosan/sMMt composites. As revealed in Fig. 6, the rod-like structure of either chitosan or chitosan/sMMt nanocomposites was observed, probably due to the high rate of phase transfer from liquid to solid. The surface of chitosan looked smooth (Fig. 6a). However, it became rough after combining with sMMt (Fig. 6b). An agglomeration of sMMt in some spot was also seen in the SEM image of chitosan/sMMt composite, caused by the attracting force between the same polarities of sMMt.

\subsection{Effect of pH on Methylene Blue Adsorption}

The removal of methylene blue is influenced by several factors, one of which is a $\mathrm{pH}$ condition. Fig. 7 presents the dye removal percentage of the adsorbents (chitosan, sMMt, and chitosan/sMMt composites) at a different $\mathrm{pH}$ condition. The chitosan worked both in acid $(\mathrm{pH}=3)$ and basic $(\mathrm{pH}=9)$ condition with dye removal of $56.22 \%$ and $71.66 \%$, respectively. However, the dye removal of MB by sMMt was predominant at basic condition $(\mathrm{pH}=11)$ about $93.99 \%$. The adsorption of dyes was influenced by the charges of both dye molecules and the surface of the adsorbent. The chitosan had amines (tended to be positively charge) and hydroxyl (negatively charge). Meanwhile, the clay minerals are rich of hydroxyl groups, which are mainly negative charges [27]. Therefore, the chitosan is capable of absorbing MB strongly at both acid and basic condition. Meanwhile, the sMMt dominantly adsorbs the MB at basic condition. Compared to the sMMt, adsorption capacity of chitosan is much lower. Therefore, an addition of sMMt into chitosan polymer is expected to improve the adsorption ability of chitosan.
As desired, the chitosan/sMMt composite had better adsorption ability compared to chitosan as evidenced by an improvement of dye removal to be $77.50 \%$. Besides it was rich of the hydroxyl group, the sMMt also contained the oxirane group, which contributed to increase the basicity of sMMt. Therefore, the chitosan/sMMt composite had good interaction with acid properties of $\mathrm{MB}$ dyes at higher $\mathrm{pH}$ condition [37]. According to Feddal et al. [38], at higher pH,

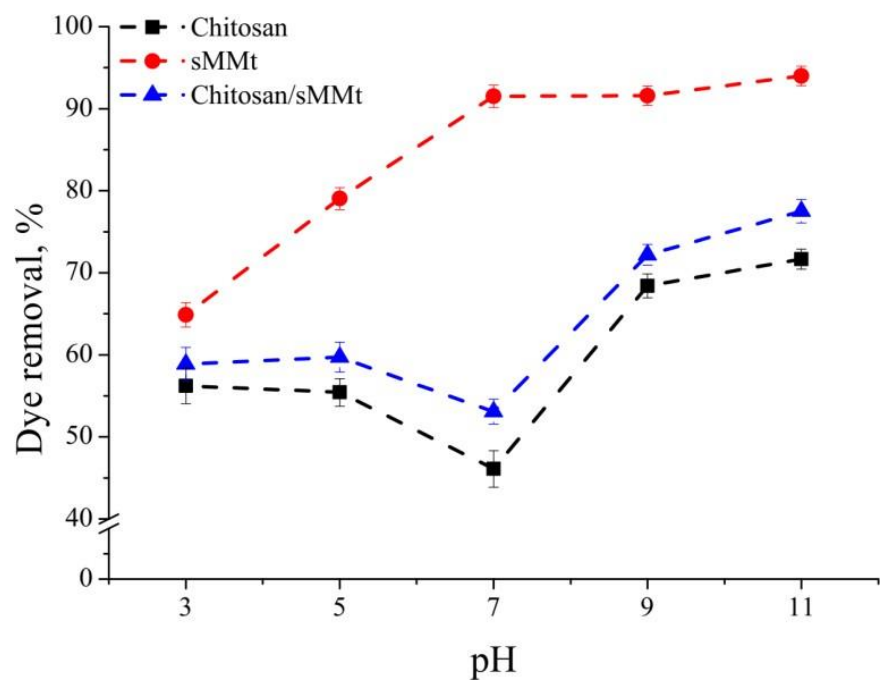

Fig. 7 Effect of pH toward methylene blue dye removal by chitosan, sMMt, and chitosan/sMMt

the $-\mathrm{OH}$ groups on clay in solution becomes negative charge due to deprotonation, which facilitates the attachment of methylene blue onto the adsorbent surface.

\subsection{Adsorption kinetics}

The adsorption contact time is an important parameter to study in adsorption process. This determines the adsorption kinetic mechanism. Fig. 8 clarifies the effect of contact time towards the adsorption capacity of chitosan, sMMt, and 
chitosan/sMMt composites. All adsorbents have rapid MB adsorption rate indicated by a high adsorption capacity at the initial stage of adsorption (5 minutes). Chitosan has the adsorption capacity of $9.13 \mathrm{mg} \mathrm{g}^{-1}$ at the initial time, while

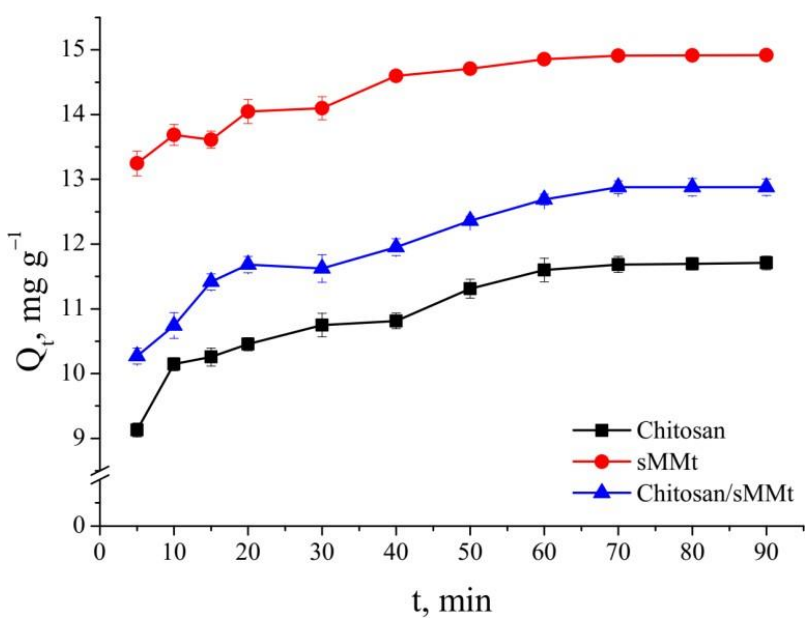

Fig. 8 Effect of adsorption contact time toward the adsorption capacity of chitosan, sMMt, and chitosan/sMMt

sMMt and chitosan/sMMt have 13.46 and $10.40 \mathrm{mg} \mathrm{g}^{-1}$, respectively. The adsorption of $\mathrm{MB}$ onto chitosan begins to reach equilibrium state after 60 minutes of contact time.

However, after adding sMMt, the equilibrium state is achieved at 70 minutes. As revealed, the adsorption capacity at equilibrium state of chitosan/sMMt was higher than chitosan. This condition was also found by Daraei et al. [39], which enhanced the chitosan adsorption performance by adding cloisite nano clay. The data also demonstrated that the adsorption of MB onto chitosan/sMMt is relatively faster at the initial time, but becomes slower afterward. Heraldy et al. [40] described this phenomenon as a two-stage adsorption mechanism, in which at the first stage, the adsorption of dye molecules was instantaneous, so the fast stage occurred. At the second phase, an equilibrium was reached due to relatively small of the total reactive dye molecules or decrease of the adsorbent capacity.

To evaluate the performance of adsorbent, studies of adsorption kinetics was performed. In this research, the Lagergren and pseudo-second order were employed as a kinetic model to determine the adsorption mechanism and its adsorption rate by fitting both of these models. The Lagergren and pseudo-second order equation were expressed as equation 2 and 3 [41]:

$$
\begin{gathered}
\log \left(\mathrm{q}_{\mathrm{e}}-\mathrm{q}_{\mathrm{t}}\right)=\log \mathrm{q}_{\mathrm{e}}-\left(\mathrm{k}_{\mathrm{t}} / 2.303\right) \mathrm{t} \\
\mathrm{t} / \mathrm{q}_{\mathrm{t}}=\left(1 / \mathrm{k}_{2} \mathrm{Q}_{\mathrm{e}}{ }^{2}\right)+\left(\mathrm{t} / \mathrm{Q}_{\mathrm{e}}\right)
\end{gathered}
$$

where $\mathrm{q}_{\mathrm{e}}$ and $\mathrm{q}_{\mathrm{t}}$ is the amount of dye adsorbed at equilibrium and $\mathrm{t}$ time $\left(\mathrm{mg} \mathrm{g}^{-1}\right), \mathrm{t}$ is the contact time $(\mathrm{min})$ and $\mathrm{Q}_{\mathrm{e}}$ is adsorption capacity at equilibrium.

The Lagergren kinetic rate $\left(\mathrm{k}_{1}\right)$ was generated from $\mathrm{t}$ versus $\log \left(\mathrm{q}_{\mathrm{e}}-\mathrm{q}_{\mathrm{t}}\right)$ plots as presented in Fig. 9a, while the pseudosecond order kinetic rate constant $\left(\mathrm{k}_{2}\right)$ and adsorption capacity at equilibrium (Qe) were determined from the slope and intercept of $t / q_{t}$ versus $t$ plot as shown in Fig. 9b. The adsorption kinetic mechanism was resolved based on the correlation coefficient (R-square). Based on the fitting linear of both models, pseudo-second order had higher R-square values than Lagergren model. Therefore, the adsorption kinetic mechanism of all adsorbents followed the pseudosecond order models which enclosed to chemisorption.

The $t / q_{t}$ versus $t$ plots for all adsorbents had a straight line, where the R-square values for each chitosan, sMMt and chitosan/sMMt composite as depicted in Table 1 were 0.999, 0.999 and 0.998 , respectively. The higher R-square values indicated the suitability of the adsorption mechanism to those models [42]. Sun et al. [43] described that the adsorption rate was mainly ruled by the dye concentration at the absorbent surface when the adsorption followed the pseudo-second order.
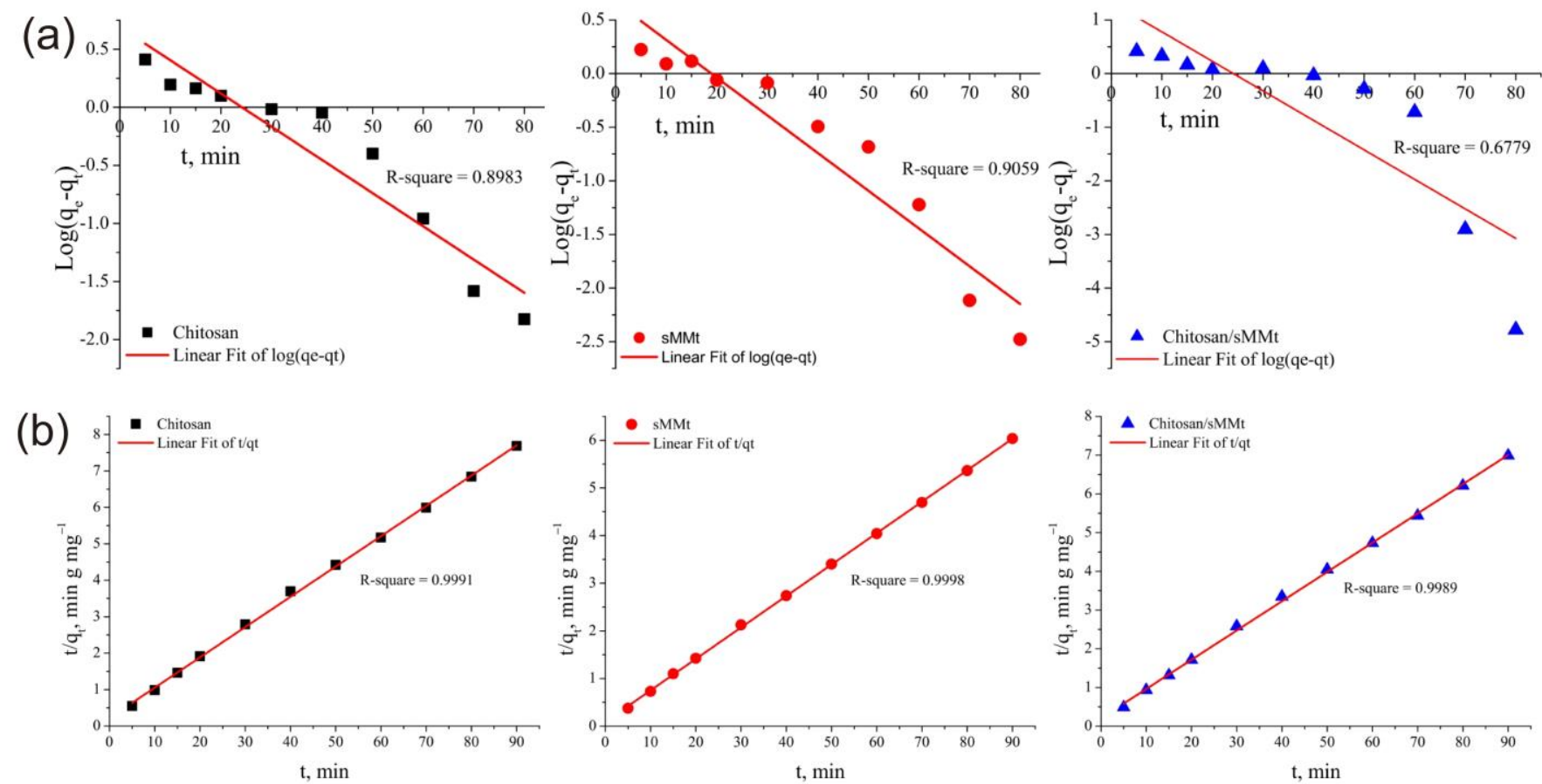

Fig. 9 (a) Lagergren and (b) pseudo-second order linear plots of chitosan, sMMt, and chitosan/sMMt 
Table 1. Kinetic parameters resulted from plotting Lagergren and pseudosecond order models

\begin{tabular}{llccc}
\hline \multicolumn{1}{c}{ Models } & \multicolumn{1}{c}{ Parameters } & Chitosan & sMMt & Chitosan/sMMt \\
\hline Lagergreen & $\mathrm{k}_{1}\left(\mathrm{~min}^{-1}\right)$ & 0.066 & 0.081 & 0.127 \\
& $\mathrm{R}$-square & 0.898 & 0.906 & 0.678 \\
\hline $\begin{array}{l}\text { Pseudo- } \\
\text { second }\end{array}$ & $\mathrm{k}_{2} \quad\left(\mathrm{~g} \mathrm{mg}^{-1}\right.$ & 0.031 & 0.047 & 0.028 \\
order & $\left.\mathrm{min}^{-1}\right)$ & & & \\
& $\mathrm{Q}_{\mathrm{e}}\left(\mathrm{mg} \mathrm{g}^{-1}\right)$ & 12.029 & 15.152 & 13.233 \\
& R-square & 0.999 & 0.999 & 0.998 \\
\hline
\end{tabular}

Table 1 presents the $\mathrm{k}_{1}, \mathrm{k}_{2}$ and $\mathrm{Q}_{\mathrm{e}}$ values of all adsorbents. The $\mathrm{k}_{2}$ of chitosan was $3.1 \times 10^{-2} \mathrm{~g} \mathrm{mg}^{-1} \mathrm{~min}^{-1}$. The addition of sMMt into chitosan slightly decreased the $\mathrm{k}_{2}$ value to be 2.8 $\mathrm{x} 10^{-2} \mathrm{~g} \mathrm{mg}^{-1} \mathrm{~min}^{-1}$. However, the $\mathrm{Q}_{\mathrm{e}}$ value of chitosan/sMMt increased by $10 \%$. It should be noted that MMt as one of the layered aluminosilicate materials was reported by previous research as a good adsorbent for dyes removal due to providing a high surface area and porous structure [44]. This then led MMt to have a high adsorption capacity toward cationic dyes. Moreover, the presence of negative charges on the MMt surfaces also enhances their ability to absorb and to interact with cationic dyes. In addition, the presence of the oxirane ring of GPTMS organosilane contributes to the adsorption of MB. By these reasons, the chitosan supported by sMMt has high adsorption capacity compared to the chitosan.

\section{Conclusion}

The silylated-montmorillonite (sMMt) has been successfully synthesized evidenced by FTIR, XRD and elemental analysis characterization. The presence of sMMt on chitosan (chitosan/sMMt composites) had a positive impact on dye removal. The optimum $\mathrm{pH}$ condition of the $\mathrm{MB}$ adsorption was reached at basic condition $(\mathrm{pH} 11)$. The adsorption kinetic mechanism followed the pseudo-second order indicating that the chemisorption played the role. The adsorption kinetic rate $\mathrm{k}_{2}$ and adsorption capacity $\mathrm{Q}_{\mathrm{e}}$ of chitosan/sMMt were found to be $2.8 \times 10^{-2} \mathrm{~g} \mathrm{mg}^{-1} \mathrm{~min}^{-1}$ and $13.23 \mathrm{mg} \mathrm{g}^{-1}$, respectively. The presence of sMMt on chitosan matrix was able to improve the $\mathrm{Q}_{\mathrm{e}}$ by $10 \%$ compared to chitosan.

\section{Acknowledgements}

Authors would like to acknowledge to Directorate General of Higher Education for the funding (PKM research grant 2016), and Universitas Sebelas Maret.

\section{References}

1. Y. Yao, F. Xu, M. Chen, Z. Xu, Z. Zhu, Adsorption behavior of methylene blue on carbon nanotubes, Bioresour. Technol. 101 (2010) 3040-3046.

2. O. J. Hao, H. Kim, P.-C. Chiang, Decolorization of Wastewater, Crit.
Rev. Environ. Sci. Technol. 30 (2000) 449-505.

3. A. K. Tripathi, N. S. K. Harsh, N. Gupta, Fungal treatment of industrial effluents: a mini-review, Life Sci. J. 4 (2007) 78-81.

4. V. Ponnusami, R. Madhuram, V. Krithika, S. N. Srivastava, Effects of process variables on kinetics of methylene blue sorption onto untreated guava (Psidium guajava) leaf powder: Statistical analysis, Chem. Eng. J. 140 (2008) 609-613.

5. M. Rafatullah, O. Sulaiman, R. Hashim, A. Ahmad, Adsorption of methylene blue on low-cost adsorbents: A review, J. Hazard. Mater. 177 (2010) 70-80.

6. T. Robinson, G. McMullan, R. Marchant, P. Nigam, Remediation of dyes in textile effluent: A critical review on current treatment technologies with a proposed alternative, Bioresour. Technol. 77 (2001) 247-255.

7. B. Shi, G. Li, D. Wang, C. Feng, H. Tang, Removal of direct dyes by coagulation: The performance of preformed polymeric aluminum species, J. Hazard. Mater. 143 (2007) 567-574.

8. A. Akbari, J. C. Remigy, P. Aptel, Treatment of textile dye effluent using a polyamide-based nanofiltration membrane, Chem. Eng. Process. Process Intensif. 41 (2002) 601-609.

9. A. Bes-Piía, J. A. Mendoza-Roca, M. I. Alcaina-Miranda, A. Iborra-Clar, M. I. Iborra-Clar, Combination of physico-chemical treatment and nanofiltration to reuse wastewater of a printing, dyeing and finishing textile industry, Desalination. 157 (2003) 73-80.

10. V. K. Gupta, R. Jain, A. Mittal, T. A. Saleh, A. Nayak, S. Agarwal, S. Sikarwar, Photo-catalytic degradation of toxic dye amaranth on TiO2/UV in aqueous suspensions, Mater. Sci. Eng. C. 32 (2012) 12-17.

11. A. Bouarioua, M. Zerdaoui, Photocatalytic activities of TiO2 layers immobilized on glass substrates by dip-coating technique toward the decolorization of methyl orange as a model organic pollutant, J. Environ. Chem. Eng. 5 (2017) 1565-1574.

12. J. Labanda, J. Sabaté, J. Llorens, Modeling of the dynamic adsorption of an anionic dye through ion-exchange membrane adsorber, J. Memb. Sci. 340 (2009) 234-240.

13. W. S. Wan Ngah, L. C. Teong, M. A. K. M. Hanafiah, Adsorption of dyes and heavy metal ions by chitosan composites: A review, Carbohydr. Polym. 83 (2011) 1446-1456.

14. Z. M. Lazim, E. Mazuin, T. Hadibarata, Z. Yusop, The removal of methylene blue and remazol brilliant blue $r$ dyes by using orange peel and spent tea leaves, Jurnal Teknologi 11 (2015) 129-135.

15. N. A. Rahmat, A. A. Ali, Salmiati, N. Hussain, M. S. Muhamad, R. A. Kristanti, T. Hadibarata, Removal of Remazol Brilliant Blue $R$ from Aqueous Solution by Adsorption Using Pineapple Leaf Powder and Lime Peel Powder, Water. Air. Soil Pollut. 227 (2016).

16. M. A. Ahmad, R. Alrozi, Optimization of preparation conditions for mangosteen peel-based activated carbons for the removal of Remazol Brilliant Blue R using response surface methodology, Chem. Eng. J. 165 (2010) 883-890.

17. L. Wang, A. Wang, Adsorption characteristics of Congo Red onto the chitosan/montmorillonite nanocomposite, J. Hazard. Mater. 147 (2007) 979-985.

18. H. Y. Zhu, R. Jiang, L. Xiao, Adsorption of an anionic azo dye by chitosan/kaolin $/ \gamma-\mathrm{Fe}_{2} \mathrm{O}_{3}$ composites, Appl. Clay Sci. 48 (2010) 522 526.

19. G. Crini, P. M. Badot, Application of chitosan, a natural aminopolysaccharide, for dye removal from aqueous solutions by adsorption processes using batch studies: A review of recent literature, Prog. Polym. Sci. 33 (2008) 399-447.

20. I. M. Lipatova, L. I. Makarova, A. A. Yusova, Adsorption removal of anionic dyes from aqueous solutions by chitosan nanoparticles deposited on the fibrous carrier, Chemosphere. 212 (2018) 1155-1162. 
21. XinxinYang, Y. Li, H. Gao, C. Wang, X. Zhang, H. Zhou, One-step fabrication of chitosan-Fe(OH)3 beads for efficient adsorption of anionic dyes, Int. J. Biol. Macromol. 117 (2018) 30-41.

22. R. C. da Silva, S. B. de Aguiar, P. L. R. da Cunha, R. C. M. de Paula, J. P. A. Feitosa, Effect of microwave on the synthesis of polyacrylamide-gchitosan gel for azo dye removal, React. Funct. Polym. 148 (2020) 104491.

23. A. Mokhtar, S. Abdelkrim, A. Djelad, A. Sardi, B. Boukoussa, M. Sassi, A. Bengueddach, Adsorption behavior of cationic and anionic dyes on magadiite-chitosan composite beads, Carbohydr. Polym. 229 (2020) 115399.

24. A. Gürses, S. Karaca, Ç. Doğar, R. Bayrak, M. Açikyildiz, M. Yalçin, Determination of adsorptive properties of clay/water system: Methylene blue sorption, J. Colloid Interface Sci. 269 (2004) 310-314.

25. W. T. Tsai, C. Y. Chang, C. H. Ing, C. F. Chang, Adsorption of acid dyes from aqueous solution on activated bleaching earth, J. Colloid Interface Sci. 275 (2004) 72-78.

26. A. Gürses, Ç. Doğar, M. Yalçin, M. Açikyildiz, R. Bayrak, S. Karaca, The adsorption kinetics of the cationic dye, methylene blue, onto clay, J. Hazard. Mater. 131 (2006) 217-228.

27. G. K. Sarma, S. SenGupta, K.G. Bhattacharyya, Methylene blue adsorption on natural and modified clays, Sep. Sci. Technol. 46 (2011) 1602-1614.

28. A. Nejib, D. Joelle, A. Fadhila, G. Sophie, T.-A. Malika, Adsorption of anionic dye on natural and organophilic clays: effect of textile dyeing additives, Desalin. Water Treat. (2014) 1-16.

29. M. A. Moreira, K. J. Ciuffi, V. Rives, M. A. Vicente, R. Trujillano, A. Gil, S. A. Korili, E. H. de Faria, Effect of chemical modification of palygorskite and sepiolite by 3-aminopropyltriethoxisilane on adsorption of cationic and anionic dyes, Appl. Clay Sci. 135 (2017) 394-404

30. M. R. Acocella, C. E. Corcione, A. Giuri, M. Maggio, A. Maffezzoli, G. Guerra, Graphene oxide as a catalyst for ring opening reactions in amine crosslinking of epoxy resins, RSC Adv. 6 (2016) 23858-23865.

31. Y. N. Bespalko, E. N. Shved, Experimental and theoretical study on the kinetics and mechanism of the amine-catalyzed reaction of oxiranes with carboxylic acids, React. Kinet. Mech. Catal. 126 (2019) 903-919.

32. S. Bakhtin, E. Shved, Y. Bespalko, T. Tyurina, V. Palchykov, Detailing the elementary stages in the oxirane ring opening reactions with carboxylic acids catalyzed by tertiary amines, J. Phys. Org. Chem. e4071 (2020) 1-14.

33. P. Yuan, P.D. Southon, Z. Liu, M. E. R. Green, J. M. Hook, S. J. Antill, C. J. Kepert, Functionalization of halloysite clay nanotubes by grafting with ??-aminopropyltriethoxysilane, J. Phys. Chem. C. 112 (2008) 15742-15751.

34. N. N. Herrera, J. M. Letoffe, J. P. Reymond, E. Bourgeat-Lami, Silylation of laponite clay particles with monofunctional and trifunctional vinyl alkoxysilanes, J. Mater. Chem. 15 (2005) 863.

35. M. Ghiyasiyan-Arani, M. Salavati-Niasari, Effect of Li2CoMn3O8 Nanostructures Synthesized by a Combustion Method on Montmorillonite K10 as a Potential Hydrogen Storage Material, J. Phys. Chem. C. 122 (2018) 16498-16509.

36. F. F. Wang, J. Liu, H. Li, C. L. Liu, R. Z. Yang, W. S. Dong, Conversion of cellulose to lactic acid catalyzed by erbium-exchanged montmorillonite K10, Green Chem. 17 (2015) 2455-2463.

37. Ü. Geçgel, H. Kolancılar, Adsorption of Remazol Brilliant Blue $R$ on activated carbon prepared from a pine cone, Nat. Prod. Res. 26 (2012) 659-664.

38. I. Feddal, a. Ramdani, S. Taleb, E. M. Gaigneaux, N. Batis, N. Ghaffour, Adsorption capacity of methylene blue, an organic pollutant, by montmorillonite clay, Desalin. Water Treat. (2013) 1-8.

39. P. Daraei, S. S. Madaeni, E. Salehi, N. Ghaemi, H. S. Ghari, M. A. Khadivi, E. Rostami, Novel thin film composite membrane fabricated by mixed matrix nanoclay/chitosan on PVDF microfiltration support: Preparation, characterization and performance in dye removal, J. Memb. Sci. 436 (2013) 97-108.

40. E. Heraldy, S.J. Santosa, Triyono, K. Wijaya, Anionic and cationic dyes removal from aqueous solutions by adsorption onto synthetic $\mathrm{Mg} / \mathrm{Al}$ hydrotalcite-like compound, Indones. J. Chem. 15 (2015) 234-241.

41. K. G. Bhattacharyya, A. Sharma, Azadirachta indica leaf powder as an effective biosorbent for dyes: A case study with aqueous Congo Red solutions, J. Environ. Manage. 71 (2004) 217-229.

42. C. A. P. Almeida, N. A. Debacher, A. J. Downs, L. Cottet, C. A. D. Mello, Removal of methylene blue from colored effluents by adsorption on montmorillonite clay, J. Colloid Interface Sci. 332 (2009) 46-53.

43. S. Sun, A. Wang, Adsorption kinetics of $\mathrm{Cu}(\mathrm{II})$ ions using $\mathrm{N}, \mathrm{O}-$ carboxymethyl-chitosan, J. Hazard. Mater. 131 (2006) 103-111.

44. C. C. Wang, L. C. Juang, T. C. Hsu, C. K. Lee, J. F. Lee, F. C. Huang, Adsorption of basic dyes onto montmorillonite, J. Colloid Interface Sci. 273 (2004) 80-86. 